\title{
Forjando nación desde abajo: violencia e identi- dades en el País Vasco y el Ulster ${ }^{1}$
}

\author{
Raúl LóPez Romo \\ Ikerbasque / Universidad del País Vasco \\ raul.lopez@ehu.es \\ Barbara VAN DER LEEUW \\ Universidad del País Vasco \\ barbara.vanderleeuw@ehu.es
}

Recibido: 05/05/2013

Aceptado:10/06/2013

\section{RESUMEN}

En Irlanda del Norte la principal línea divisoria de la población es la pertenencia a una categoría específica, la de comunidad político-religiosa. En diversas ocasiones se ha comparado la situación del País Vasco con la del Ulster. En este artículo comprobaremos si la sociedad vasca podría ser clasificada de la misma manera que la norirlandesa. Pretendemos responder a la siguiente pregunta principal: ¿en qué medida el nacionalismo desde abajo en Irlanda del Norte y Euskadi se parece o difiere respecto a la construcción de comunidades político-religiosas? Nos centraremos en la evolución de las alas radicales de los nacionalismos vasco, español, británico e irlandés en la segunda mitad del siglo XX.

Palabras clave: País Vasco, Ulster, comunidad político-religiosa, nacionalismo desde abajo, políticas de la muerte, violencia política, giro local.

\section{Making the Nation from below: Violence and Identities in the Basque Country and Ulster}

\begin{abstract}
In Northern Ireland the population has been classified into different communities following political/ religious categories. Scholars, as well as the people in general, have usually compared the situation in the Basque Country with that existing in Ulster. In this article we explore whether Basque society might be classified using the kind of categories valid for the Northern Irish, trying to address the following question: To what extent does Northern Ireland's "nationalism from below" reflect the same kind of political-religious communities prevailing in the Basque Country? In order to find an answer we focus on the evolution of radical nationalist groups in the Basque Country, Spain, the United Kingdom and Ireland in the second half of the twentieth century.
\end{abstract}

Key words: Basque Country, Ulster, Political-Religious Community, Nationalism from below, Politics of the Dead, Political Violence, Local Turn.

1 Hemos realizado este trabajo gracias a la disponibilidad de un contrato postdoctoral (en el caso de Raúl López Romo) y un contrato predoctoral (en el caso de Barbara van der Leeuw) de la Dirección de Política Científica del Gobierno Vasco. Nuestro texto forma parte de las investigaciones del Grupo de Historia Social y Política del País Vasco contemporáneo (IT-429-10) y del proyecto "El proceso de nacionalización española en el País Vasco contemporáneo (1808-1980): giro local y conflicto nacional” (HAR2011-30399), dirigidos por el catedrático de la UPV/EHU Luis Castells. Agradecemos las sugerencias de Gaizka Fernández Soldevilla, Adrian Guelke y los dos evaluadores anónimos de Cuadernos de Historia Contemporánea. Damos asimismo las gracias a Jesús Casquete por su invitación a reflexionar sobre si en Euskadi existe o no una "sociedad paralela" abertzale, cuestión que está en el origen de este artículo. 


\section{Referencia normalizada}

López Romo, Raúl y Leeuw, Barbara van der. (2013). "Forjando nación desde abajo: violencia e identidades en el País Vasco y el Ulster". Cuadernos de Historia Contemporánea, 35, pp. 15-39.

Sumario: Introducción. 1. Descanse sin paz: la muerte no significa el final. 2. ¿Qué fue del nacionalismo español en el País Vasco? 3. ¿Sociedades profundamente divididas? 4. ¿Cuándo y por qué surgieron las comunidades político-religiosas? 5. Euskadi y el Ulster: poco en común. 6. Bibliografía.

\section{Introducción}

Recorriendo las calles de Belfast uno tropieza frecuentemente con taxistas que guían a los visitantes por los abundantes murales que han pintado los nacionalistas irlandeses y británicos. En el Irish Republican History Museum, que está situado en el área de Falls Road y constituye una parada obligatoria del tour, nos encontramos con uno de ellos explicando detalladamente a dos estadounidenses la colección. El material expuesto consiste, entre otras cosas, en manualidades hechas por los prisioneros del IRA Provisional (entre otras, por las mujeres que estaban encarceladas en la prisión de Armagh), varios tipos de armas, carteles y artículos de periódicos reflejando los sucesos durante los Troubles. Al hojear los miles de recortes de prensa, se acerca el guía, coge una carpeta y muestra orgulloso a sus dos oyentes una fotografía de una marcha republicana en la que aparecía una versión joven de él. Entonces nos damos cuenta de que muchos de los análisis de la bibliografía académica sobre la situación en Irlanda del Norte son insuficientes para entender el impacto de los Troubles en la sociedad. Gracias a sus emotivas explicaciones ese hombre canoso nos ha hecho ver el protagonismo del ciudadano "normal", es decir, la exaltación del individuo anónimo que hace algo por el grupo y así es recordado 2 .

En Irlanda del Norte la principal línea divisoria de la población no es la riqueza, ni el color de piel, ni el idioma, sino la pertenencia a una categoría específica, la de comunidad político-religiosa. En diversas ocasiones se ha comparado la situación de Euskadi con la del Ulster. En este trabajo comprobaremos si la sociedad vasca podría ser clasificada de la misma manera que la norirlandesa. Pretendemos responder a la siguiente pregunta principal: ¿en qué medida el nacionalismo desde abajo en Irlanda del Norte y Euskadi se parece o difiere respecto a la construcción de comunidades político-religiosas? Esta cuestión abarca la evolución de los movimientos nacionalistas vasco, irlandés, español y británico (unionista). Nos centraremos en la vertiente radical de dichos movimientos, con especial atención a la segunda mitad del siglo XX.

Cuando hablamos de comunidad político-religiosa estamos ante un grado superlativo de identidad, favorecido por lo que podemos denominar una integración por inmersión: los sujetos se sumergen en un colectivo donde se nacionalizan de una forma exclusivista, con una intensa vocación movilizadora y que frecuentemente se experimenta desde la infancia, en múltiples expresiones de la vida cotidiana. Hemos

2 Sobre la importancia de la experiencia individual de la idea de nación vid. las reflexiones de MOLINA, Fernando: "La nación desde abajo. Nacionalización, individuo e identidad nacional", Ayer, 90 (2013), pp. 39-63. 
elegido tratar esta materia apoyándonos en buena medida en el estudio de las políticas de la muerte y, más concretamente, en los lugares de memoria relacionados con ellas. Nos centramos en los murales para el caso norirlandés porque son una de las expresiones más explícitas de los nacionalismos enfrentados y porque en ellos están resumidas las principales tramas del conflicto territorial ${ }^{3}$. Para el caso del País Vasco recurrimos a una nómina más variada de fuentes: monumentos a los caídos, conmemoraciones, funerales de víctimas del terrorismo... Esta vía de análisis ayuda a entender procesos históricos que se produjeron en los tres campos de interés de nuestra investigación, a saber, la cultura, la sociedad y la política. Así se puede aprehender el desarrollo de las sociedades en su complejidad, sus cambios y continuidades, aparte de sus códigos morales ${ }^{4}$.

Primero expondremos el marco teórico, en el cual penetramos en la instrumentalización de la figura del muerto por diferentes ideologías. A continuación trataremos la presencia o ausencia de diferentes comunidades político-religiosas en las dos regiones a estudio, así como los factores que las explican. Finalmente profundizaremos en la razón de la profunda influencia que el ejemplo de Irlanda ha ejercido sobre el nacionalismo vasco.

\section{Descanse sin paz: la muerte no significa el final}

En este apartado nos centramos en el rol que los movimientos políticos reservan a los muertos en la construcción de identidades grupales, la invocación de las emociones, la creación de lugares de memoria en el espacio público y el fortalecimiento de la cohesión.

El fallecido puede "servir" en todos estos campos gracias a su gran valor simbólico: es relativamente sencillo "aprovecharse" de él porque ya no tiene capacidad de explicar el sentido de su recorrido vital, ni de responder a las diferentes interpretaciones de sus acciones y palabras 5 . A decir de Vangelis Angelis, "al muerto se le puede teñir, según la ocasión, con los colores adecuados que "vengan bien" al vivo, de modo que sirva a los fines de éste" ". Así, el difunto ya no es responsable directo de "la ratificación o modificación de su sentido", algo que es asumido por los vivos.

3 Los murales del Ulster no son únicamente artefactos artísticos, sino que están íntimamente ligados a la actividad política y al conflictivo paisaje nacional: "For example, the painting or dedication of murals themselves has frequently led to political conflict, while murals often become the first victims of political conflict", ROLSTON, Bill: "Changing the Political Landscape: Murals and Transition in Northern Ireland", Irish Studies Review, 11-1 (2003), p. 3.

4 BLACK, Monica: Death in Berlin: From Weimar to Divided Germany, Cambridge, Cambridge University Press, 2010, p. 271.

5 VERDERY, Katherine: The Political Lives of Dead Bodies: Reburial and Postsocialist Change, New York, Columbia University Press, 1999, p. 29.

6 ANGELIS, Vangelis: "Seis entierros y un réquiem: El ceremonial de la muerte política en la Grecia de 1936”, en Jesús CASQUETE y Rafael CRUZ (eds.): Políticas de la muerte: Usos y abusos del ritual fúnebre en la Europa del siglo XX, Madrid, Los Libros de la Catarata, 2009, p. 231. 
Manuel Fernández del Riesgo denomina a este fenómeno "la metamorfosis de nuestro ser en destino"?.

En los funerales y conmemoraciones se suelen generar fuertes emociones, sentimientos de inseguridad, miedo y duelo, al igual que preocupaciones sobre los significados que habría que atribuir a la vida y la muerte en general ${ }^{8}$. Al fenecer alguien que perteneció al grupo, en cierta manera sus camaradas se sienten amenazados y pretenden mostrar solidaridad. El luto y el llanto compartido sirven para reforzar los lazos sociales y con ellos se manifiesta la dependencia del individuo frente al colectivo9. De esta manera el muerto queda integrado entre los vivos. La instrumentalización es posible porque se parte de la idea de "que el finado, era, es y será nosotros, y por eso mismo es y será nuestro y no de otros"10.

La defunción de una persona significa que ya no hablamos de ella en términos de presente sino de pasado. Por eso las políticas de la muerte siempre son al mismo tiempo políticas de la memoria ${ }^{11}$. El fallecido puede permanecer entre los vivos si se siguen haciendo conexiones entre un mundo y otro, las cuales se pueden establecer, por ejemplo, mediante lugares de memoria. Estos últimos incorporan recuerdos colectivos de importancia. Y más aún en el caso de los movimientos nacionalistas, puesto que sus demandas son de índole territorial. Mediante los santuarios patrióticos se consigue integrar los mitos históricos en el paisaje. De esta manera, dentro del marco de la patria se combinan historia, geografía y memoria colectiva. De todas formas, la relevancia no reside en los lugares mismos, sino en la transmisión de la idea de comunidad entre muertos y vivos. Se pretende dar forma a un sentido de solidaridad, una función que también tienen otros símbolos, como las banderas y las canciones ${ }^{12}$.

En los lugares de memoria los muertos son representados a menudo como mártires. Estos informan a los vivos "de la tarea que queda por hacer, de la lucha que hay que continuar, de los propósitos que debemos imponernos, de las lecciones que aprendieron" ${ }^{13}$. La construcción de mártires se produce, por un lado, en sociedades que no son muy estables y pasan por procesos de reestructuración a nivel cultural, económico y político. Por otro lado, tal práctica abunda también en sociedades que contienen un gran número de gente adoctrinada y dispuesta a morir por una fe, ya sea de tipo político-social, religioso, nacional, o por una combinación de varios de estos ideales ${ }^{14}$.

\footnotetext{
7 Las citas en FERNÁNDEZ DEL RIESGO, Manuel: Antropología de la muerte: Los límites de la razón y el exceso de la religión, Madrid, Síntesis, 2007, p. 286.

8 VERDERY, Katherine: The Political Lives of Dead Bodies..., op. cit., p. 31.

9 BARLEY, Nigel: Bailando sobre la tumba: Encuentros con la muerte, Barcelona, Editorial Anagrama, 2000, p. 32.

10 CASQUETE, Jesús: "El poso agridulce de la ausencia: Vectores de las políticas de la muerte", en Jesús CASQUETE y Rafael CRUZ (eds.): Políticas de la muerte..., op. cit., p. 340.

11 Ibidem, p. 342.

12 STYNEN, Andreas: Een Geheugen in Fragmenten: Heilige Plaatsen van de Vlaamse Beweging, Tielt, Lannoo, 2005, pp. 23, 25 y 246.

13 BERTMAN, Sandra L.: "Comunicación con los muertos: experiencia en el arte, la literatura y el canto", en Robert KASTENBAUM (dir.): Entre la vida y la muerte, Barcelona, Herder, 1984, pp. 170 y $202-203$.

14 SMITH, Lacey Baldwin: Fools, Martyrs, Traitors: The Story of Martyrdom in the Western World, Evanston, Illinois, Northwestern University Press, 1997, p. 18.
} 
Louis-Vincent Thomas señala que el difunto también puede subsistir mediante rituales fúnebres ${ }^{15}$. El mensaje que se suele transmitir en ellos es fundamentalmente de índole identitaria, está dirigido al propio colectivo más que al resto del mundo. Prevalecen los esfuerzos por vigorizar los nexos sociales más que por transmitir demandas políticas hacia fuera, hacia las autoridades. La liturgia fúnebre sirve para recordar que los miembros del grupo son depositarios de un compromiso moral ${ }^{16}$. Sin embargo, hablamos de una muerte social si el fallecido deja de ser un agente activo en la vida pública ${ }^{17}$.

La muerte puede ser una faceta esencial de la contienda política en contextos de fuertes protestas y movilizaciones en la calle, cuando grupos sociales enfrentados ideológicamente luchan por el mismo terreno ${ }^{18}$. Los lugares a los que se ha atribuido un significado especial, una memoria, en algunas ocasiones son destrozados. Esta conducta se debe tanto al deseo de acabar con los recuerdos de los adversarios (damnatio memoriae) como a los cambios políticos que conducen a cambios simbólicos ${ }^{19}$.

\section{2. ¿Qué fue del nacionalismo español en el País Vasco?}

La relación entre transformaciones políticas y simbólicas se demostró en la Transición a la democracia en Euskadi, cuando no sólo la iconografía de la dictadura, sino toda la española, prácticamente desapareció de la escena. Para entender tal proceso hay que volver la vista atrás. No nos vamos a extender en las razones del declinar de la movilización franquista, lo que se hace a fondo en otro artículo de este dossier. Pero sí debemos apuntar los factores que explican por qué el nacionalismo potenciado por el franquismo siguió un camino inverso al de las comunidades político-religiosas aquí estudiadas.

Tras la victoria bélica, el franquismo monopolizó los símbolos patrios mientras hacía damnatio memoriae con los restos del nacionalismo español liberal y progresista. Durante la dictadura, la principal base social del nacionalismo español en el País Vasco fue el carlismo. Éste potenciaba una forma de regionalismo que amparaba las dobles identidades territoriales o la defensa de la foralidad ${ }^{20}$. Pero desde los inicios de la dictadura también hubo una corriente uniformizadora que, en la práctica, fue reduciendo dichas muestras regionalistas a ornamento folclórico de eventos puntuales.

15 THOMAS, Louis-Vincent: Rites de mort: Pour la paix des vivants, Paris, Fayard, 1985, p. 215. Sobre la mayor importancia de los rituales que los objetos materiales para mantener viva la memoria: FORTY, Adrian: "Introduction", en Adrian FORTY y Susanne KÜCHLER (eds.): The Art of Forgetting, Oxford, Berg, 1999, p. 2.

16 CASQUETE, Jesús: "El poso agridulce...”, op. cit., p. 341.

17 MULKAY, Michael: "Social Death in Britain", en David CLARK (ed.): The Sociology of Death: Theory, Culture, Practice, Oxford, Blackwell, 1993, p. 33.

18 CASQUETE, Jesús: "El poso agridulce...", op. cit., p. 337.

19 RADER, Olaf B.: "Viejos huesos con nuevos significados", en CASQUETE, Jesús y CRUZ, Rafael (eds.): Politicas de la muerte..., op. cit., p. 32.

20 MOLINA, Fernando: "De la historia a la memoria. El carlismo y el problema vasco (1868-1979)", en VVAA: El carlismo en su tiempo: geografias de la contrarrevolución, Pamplona, Gobierno de Navarra, 2008, pp. 167-204. 
Hubo, por tanto, una retroalimentación de nacionalismos homogeneizadores que se amplificó con los primeros atentados de ETA. Este proceso se acentuó desde 1968, fecha tanto del primer asesinato cometido por esa organización, como del deceso del llamado "Primer Mártir de la Revolución": el etarra Txabi Etxebarrieta ${ }^{21}$. En esos años, una parte de los ataques de ETA iban dirigidos contra monumentos franquistas a los "caídos por España" en la Guerra Civil o contra supervivientes de la misma. Estos actos son un nuevo ejemplo de damnatio memoriae. Dichos lugares de memoria constituían el corazón simbólico del régimen y transmitían a diario sus principales ideales de lucha; exaltando la muerte, con toda su fuerza emotiva, como el sacrificio más grande que uno podría hacer por la patria.

La dejación de la dictadura respecto al empleo de símbolos acuñados como vascos favoreció que el abertzalismo fuera monopolizándolos, al mismo tiempo que el nacionalismo español se retraía en el País Vasco. Junto a ese desinterés también hay que mencionar la frecuente respuesta represiva del franquismo contra dichos símbolos cuando se escapaban de su control directo. Represión que convivió con intentos (insuficientes a los efectos deseados) de regeneración de un regionalismo vasco españolista. En el balance que el Gobierno Civil de Vizcaya hizo de lo ocurrido en la provincia en 1971 podemos leer:

En relación con la exteriorización de actividades de carácter localista, hay que mantener una constante restricción de toda actividad que tenga un matiz separatista, bien por su contenido o por la ideología de los organizadores. Sin embargo, es preciso canalizar los sentimientos nobles del amor a la patria chica, dentro de medios y ambientes asépticos, multiplicando y fomentando las actividades que se refieran exclusivamente al tipismo y costumbres del folklore, sin desviaciones de carácter político y subversi$\mathrm{vo}^{22}$.

En la memoria de actividades de Falange de Vizcaya correspondiente a 1962 se relatan las actividades patrióticas llevadas a cabo por la Hermandad de Alféreces Provisionales, la Asociación de Antiguos Combatientes de Vizcaya, la Hermandad de la División Azul y la Guardia de Franco. El año, se decía, era propicio para impulsar una regeneración españolista, ya que se conmemoraban los 25 años de la "liberación" de Vizcaya. Hubo ciclos de conferencias en el cine Gran Vía de Bilbao, reuniones de antiguos combatientes en lugares destacados de la guerra en el norte (los montes Saibigain, Peña Lemona y Sollube) y concentraciones en los cuarteles de Garellano, en Bilbao. Lo bélico y los caídos aparecían de nuevo en el centro de la movilización franquista. "Todo ello", se mantenía en la citada memoria, "ha venido a significar una nueva presencia de nuestros valores políticos y una nueva tensión en nuestros hombres, funcionalmente alejados del Movimiento, pudiéndose estimar, en resumen, que toda esta actualización ha vuelto a poner en pie toda la vertiente radicalmente

21 Así fue definido por sus compañeros de ETA, en HORDAGO (comp.): Documentos Y, San Sebastián, Lur, 1979, Vol. VII, p. 484 [1968].

22 Archivo del Gobierno Civil de Vizcaya (AGCV), memoria de gestión del Gobierno Civil de Vizcaya de 1971. 
española de nuestra provincia"23. Pese a vanagloriarse del supuesto éxito de dichas actividades, en esas líneas, al mismo tiempo, se reconocía la relajación de los afectos a la dictadura. Y si en 1962 los eventos populares españolistas fueron discretos, apenas seis años después el diagnóstico de las autoridades franquistas de Vizcaya es elocuente de su imparable declive:

Preocupación primordial de esta jefatura [del Movimiento Nacional en Vizcaya] es el desarrollo que está adquiriendo la propaganda separatista, junto con la difusión de numerosas publicaciones sobre Mao, Engels, Marx, Lenin, Che Guevara, etc., que tanto impacto causan en la juventud, sobre todo al no producirse acciones de propaganda de signo español que pudieran contrarrestar eficazmente los efectos perniciosos de aquella. Los afiliados al Movimiento de esta provincia, muy pocos en comparación a su número de habitantes por desgracia, se lamentan de que cada vez tengan menos resonancia las conmemoraciones de las efemérides eminentemente patrióticas, aún las de signo español simplemente ${ }^{24}$.

El tipo de nacionalismo español que predominó en el País Vasco durante la dictadura fue el impulsado básicamente desde arriba. El Nuevo Estado potenció la desmovilización de las masas y la aceptación acrítica del régimen, siendo éste uno de los factores que explican esa falta de propaganda española de la que se lamentaba el autor de la anterior cita ${ }^{25}$.

"En la guerra tu sangre, en la paz tu trabajo", se leía en una medalla militar del régimen. Así se clamaba por la continuidad del sacrificio de los acólitos en la conmemoración de los " 25 años de paz". La idea se completaba con una loa al "honor y gloria de caídos y héroes". Es decir, se ensalzaba el recuerdo de los muertos gracias a los cuales España habría disfrutado de ese periodo pacífico y se pedía de los vivos la continuación de su compromiso por la vía laboral. Los vivos y los muertos quedaban asociados y la abnegación de los últimos podía servir de ejemplo para los primeros.

Al margen de la retórica, proclamas como las susodichas se expresaban bajo unas deterioradas condiciones de vida y bajo la represión ante los intentos por mejorarlas que fluyeran fuera de los estrechos cauces del régimen ${ }^{26}$. A principios de la década de 1960 arrancó un nuevo movimiento obrero que mostraba la amplitud

23 AGCV, memoria de actividades de Falange de Vizcaya correspondiente a 1962.

24 AGCV, memoria del Gobierno Civil de Vizcaya de 1968. Subrayado nuestro.

25 Instituciones con una presencia social destacada, como el Sindicato Vertical, lo que buscaban era "sometimiento, no adhesión", no "atraerse a la masa de trabajadores, sino simplemente evitar la reproducción de la conflictividad laboral". PÉREZ, José Antonio: Los años del acero: La transformación del mundo laboral en el área industrial del Gran Bilbao (1958-1977). Trabajadores, convenios y conflictos, Madrid, Biblioteca Nueva, 2001, pp. 137 y 138.

26 Los límites de la penetración del nacional-sindicalismo en el País Vasco son visibles en el fallido intento de generalizar la experiencia del barrio bilbaíno de San Ignacio, "buque insignia de la Obra Sindical del Hogar". El nuevo Estado franquista pretendió construir allí un modelo de su ambicionada y nunca realizada comunidad nacional. El ejemplo ha sido estudiado por PÉREZ, José Antonio: "De la comunidad nacional a la comunidad de propietarios. Los límites del nacional sindicalismo", en Luis CASTELLS, Arturo CAJAL y Fernando MOLINA (eds.): El País Vasco y España: Identidades, nacionalismos y Estado (siglos XIX y XX), Bilbao, Universidad del País Vasco, 2007, pp. 215-247, la cita es de la última página. 
del descontento social, tanto en el País Vasco como en otras regiones de España. Al contrario, en Irlanda del Norte la clase trabajadora protestante (el caso más conocido son los astilleros de Belfast) mantuvo su lealtad al Estado unionista porque el status quo los privilegiaba. Pese a ser una minoría social, la mayoría de los desempleados era católica.

El franquismo, con una base social cada vez más envejecida, se encontró en el País Vasco con verdaderos problemas para enganchar con los jóvenes del baby boom. En la recta final de la dictadura se multiplicaron las protestas no solo laborales, sino también políticas y antirrepresivas, como numerosas acciones para reclamar la libertad de los presos de ETA condenados a muerte. La imposición de la pena capital, así como los malos tratos a los detenidos, potenciaron el sentimiento de venganza en una parte de los opositores.

Desde 1975 ETA fue completando su particular pedagogía de la limpieza social mediante el inicio de sendas campañas "anti-alcaldes" y "anti-chivatos". Estas ambiguas etiquetas amparaban el asesinato de personas previamente difamadas por ser "españolistas", tener amigos de la Guardia Civil, ser "conocidos antivasquistas" o por haber tenido algún cargo en la administración local o provincial bajo la dictadura. Señalando a estas víctimas, ETA trataba de culminar el proceso de construcción del enemigo españolista del pueblo vasco mediante el choque contra él de la manera más tajante posible: mediante su eliminación física. A esto hay que añadir una campaña de intimidación y acoso contra los primeros actos públicos de UCD o AP en Euskadi. Todo ello asentó una espiral de miedo y silencio en una parte de la sociedad vasca que acentuó el declive de la derecha no abertzale en Euskadi.

El nacionalismo español quedó desacreditado en Euskadi por su casi absoluta identificación con el represivo régimen franquista y por sufrir, ya en la segunda mitad de los setenta, las mencionadas prácticas de acoso. Desde la Transición dicha cultura política quedó reducida en Euskadi a la semiclandestinidad, refugiada en el anonimato del voto, con problemas para encontrar candidatos y locales donde organizar mítines ${ }^{27}$. El Estado se mostraba incapaz de proteger la vida de todos los ciudadanos. Los funerales de las víctimas del terrorismo etarra no servían para reforzar una comunidad nacionalista española inexistente, ni siquiera para hacer nación. Simbolizaban, más bien, el abandono público que padecían, el miedo y las características de una patria en retracción. Cadáveres que eran trasladados en silencio para ser enterrados en sus pueblos de origen. Mujeres de guardias civiles que exigían a las autoridades que cambiaran de destino a sus maridos. Asistentes al funeral de Jesús Velasco, jefe de la Policía Foral de Álava asesinado por ETAm en 1980, pidiendo al ministro de Defensa que contara "en Madrid cómo se muere por España en el País Vasco". Otras honras fúnebres que, ante la dejación de las insti-

27 Marcelino Oreja, Jaime Mayor Oreja y Leopoldo Barreda explican las duras condiciones que afrontó la UCD en la Euskadi de la Transición en IGLESIAS, M. ${ }^{a}$ Antonia: Memoria de Euskadi. La terapia de la verdad: todos lo cuentan todo, Madrid, Aguilar, 2009. Esas condiciones son extensibles al conjunto del centro y la derecha no abertzale. 
tuciones, fueron instrumentalizadas por extremistas de derecha, que aprovechaban el ambiente emocionalmente cargado para gritar consignas en provecho propio... ${ }^{28}$

Y tras los funerales, otra vez prevalecía el mutismo hasta que se producía una nueva víctima del terrorismo, en un bucle que conducía de la muerte biológica a la inmediatamente posterior "muerte social". El difunto, salvo para la familia, los amigos y los compañeros de trabajo, desaparecía del mapa y, en este sentido, fue desaprovechada su potencial fuerza simbólica. Solo mediante los funerales no se podía mantener activa una comunicación política entre los vivos y el muerto, sino que este vínculo habría requerido de ser alimentado constantemente mediante la creación de lugares de memoria, conmemoraciones, etc. En muchas exequias ni siquiera había rastro de simbología española ${ }^{29}$.

\section{3. ¿Sociedades profundamente divididas?}

Las muestras populares de patriotismo español en Euskadi no han resurgido públicamente hasta fechas recientes y con cuentagotas: algunas marchas "constitucionalistas” de ¡Basta Ya! o tras victorias internacionales de la selección española de fút$\mathrm{bol}^{30}$. Esta tímida revivificación tiene que ver tanto con el alejamiento cronológico del franquismo como con la respuesta al frentismo abertzale de la etapa de Estella.

Ahora bien, ni durante la dictadura ni mucho menos después de acabada ésta el nacionalismo español ha llegado a formar en el País Vasco una comunidad política, para lo cual habría requerido del establecimiento de una rutina de eventos de masas repetidos en el espacio público e impulsados desde abajo. Ha sido, más bien, una cultura política que ha contado con una vitalidad desigual dependiendo del momento y que ha estado integrada por familias procedentes de diferentes tradiciones, no siempre bien avenidas ${ }^{31}$. Un buen ejemplo de la enemistad entre esos proyectos políticos dispares es el enfrentamiento que tuvo lugar en Bilbao en 1942 entre tradicionalistas y falangistas, saldado con varios muertos durante una misa en recuerdo de los requetés fallecidos.

En el Ulster las divisiones políticas (nacionalismos enfrentados) venían exacerbadas por previas fronteras religiosas. Estas últimas aportaban generosas dosis de fundamentalismo a los asuntos públicos, con un aporte complementario de la noción de verdad de la que se sentían ungidos muchos de los rivales. Unos veían el catolicismo como una religión no democrática, férreamente dirigida por una jerarquía encabezada por el Papa de Roma. Para otros el protestantismo era una religión absolutamente confundida con un poder civil que sancionaba la discriminación de

28 Peticiones de traslados en Egin, 7 de noviembre de 1978, tras el asesinato del guardia civil Mariano Criado. El funeral de Velasco en El Correo Español-El Pueblo Vasco, 12 de enero de 1980. Según la crónica de Egin, 12 de enero de 1980, durante los actos de duelo por Velasco los gritos de "ETA asesina" fueron acallados con un siseo.

29 MOLINA, Fernando: “El nacionalismo español y la 'guerra del Norte', 1975-1981”, Historia del Presente, 13 (2009), pp. 41-54.

30 MOLINA, Fernando: “¿De dónde salieron las banderas? Reflexiones sobre 'la Roja', los vascos y el patriotismo español", Cuadernos de Alzate, 44 (2011), pp. 31-46.

31 SAZ, Ismael: "Las culturas de los nacionalismos franquistas", Ayer, 71 (2008), pp. 153-174. 
los católicos al servicio de la unión británica. A las fracturas políticas y religiosas se añadía un tercer vector: las raíces geográficas de los vecinos. Tras sofocar la revuelta gaélica-irlandesa de 1601, miles de habitantes de Inglaterra y Escocia se fueron instalando en Irlanda para evitar nuevas rebeliones (un proceso denominado plantation). Entre ellos predominaban los presbiterianos (en los condados de Antrim y Down) y los anglicanos (en Armagh y Fermanagh) ${ }^{32}$.

A partir de ahí, Brian Walker menciona no solamente la existencia de dos comunidades, sino que enfatiza las diferencias hablando de dos universos paralelos, dos identidades y dos minorías en el norte y el sur de Irlanda ${ }^{33}$. Estas divisiones han quedado culturalmente reforzadas mediante formas contrapuestas de ver la historia. Los protestantes se identifican con los vencedores de la batalla de Boyne en $1690 \mathrm{y}$ con los que lucharon en Somme durante la Primera Guerra Mundial. Y siguen marchando para conmemorar Boyne agrupados en la Orden de Orange, divulgándose así como pertenecientes a una comunidad atemporal.

Los lealistas, radicales del ala unionista, llevan casi un siglo expresando su visión del mundo en murales. Buena parte de ellos recuerda la batalla de Boyne (fig. $1)^{34}$, que enfrentó a dos pretendientes a los tronos de Inglaterra, Escocia e Irlanda: el católico Jacobo II y el protestante Guillermo III. King Billy, como popularmente se denomina a este último, suele aparecer como un campeón de su fe: vestido de rojo y armado con una lanza, montando triunfalmente un caballo blanco. Junto a la imagen del rey figura el año de la contienda, que a veces se combina con fechas recientes memorables para la comunidad unionista y que, de paso, establecen una continuidad entre 1690 y el conflicto ahora llevado por los militantes lealistas. En alguna ocasión, en lugar de Guillermo III aparece otra figura a quien se pretende enaltecer, como Michael Stone, que fue enviado a la cárcel por asesinar a tres republicanos en un funeral en Belfast en $1988^{35}$. Los murales dedicados a la batalla de Somme, que tuvo lugar en 1916, recuerdan a los muchos soldados de la 36th (Ulster) Division que murieron en ella. Se les vincula con los actuales voluntarios de la Ulster Volunteer Force y así se resalta el aspecto de la persistencia generacional.

En el fondo, los murales traslucen una práctica extendida en la vida pública norirlandesa: la instrumentalización de políticas de la muerte, en las que ocupa un lugar fundamental la figura de los mártires. Por poner otro ejemplo, la iglesia "presbiteriana libre" fundada en Belfast por Ian Paisley, reverendo y exlíder del Democratic Unionist Party, se denomina "Memorial de los Mártires" ${ }^{36}$. El caso de Paisley demuestra, asimismo, la fusión entre religión y política, las dificultades para secularizar la vida pública en Irlanda del Norte.

32 BRYAN, Dominic: Orange Parades: The Politics of Ritual, Tradition and Control, London, Pluto Press, 2000 , p. 29.

33 WALKER, Brian: A Political History of the Two Irelands: From Partition to Peace, Basingstoke/ New York, Palgrave Macmillan, 2012, p. 44.

34 ROLSTON, Bill: "Changing the Political Landscape...", op. cit., p. 6.

35 ROLSTON, Bill: Drawing Support 2: Murals of War and Peace, Belfast, Beyond the Pale Publications, 1995 , p. 2.

36 GURRUCHAGA, Iñigo: El modelo irlandés. Historia secreta de un proceso de paz, Barcelona, Península, 1998, p. 97. 


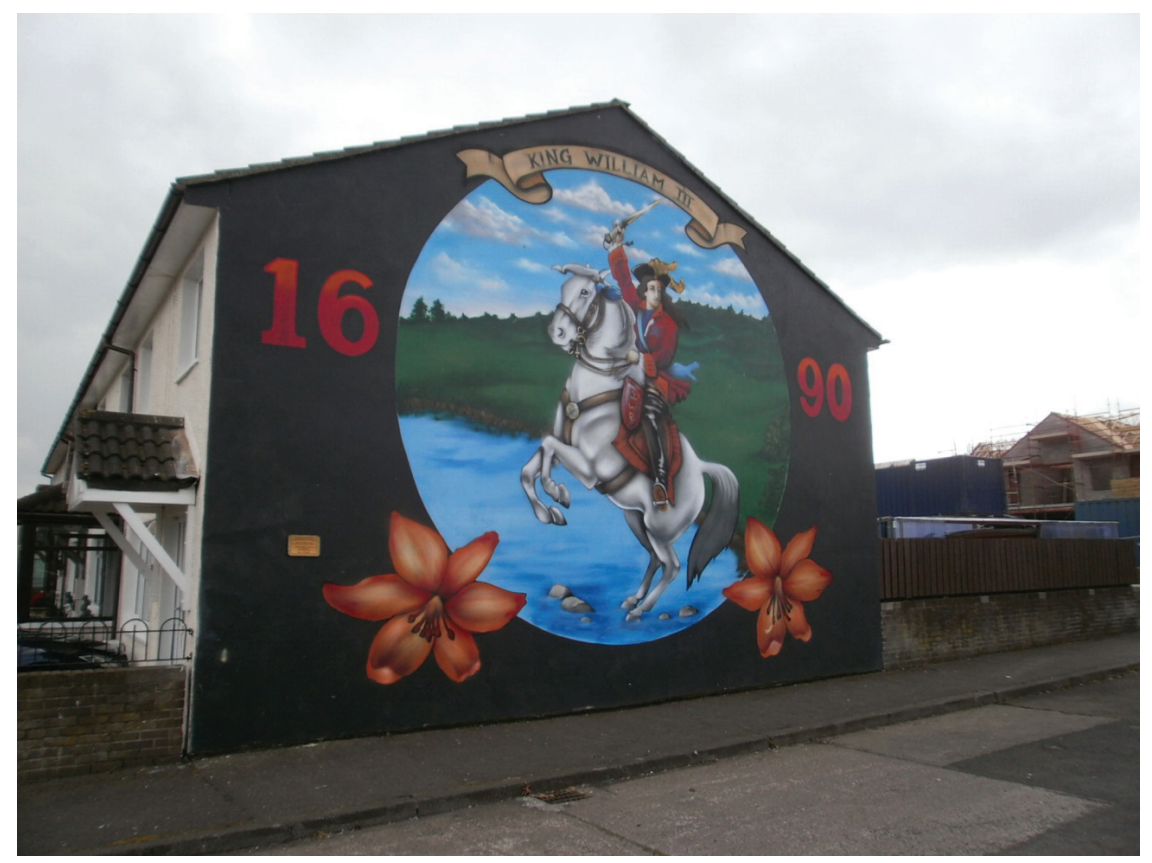

Fig. 1. Mural en conmemoración de la batalla de Boyne en Belfast (Foto: BvdL y RLR).

La vivencia en comunidad es clave para reproducir este tipo de visiones y para mantenerlas libres del contacto con los que todavía son vistos como enemigos; alejadas de los "otros", que serían irreconciliables. Los otros son los católicos, cuya corriente republicana tradicionalmente ha alimentado una cultura de derrota, potenciada por el hecho de sentirse una nación pequeña frente a un Estado grande. Los mártires a los que se exaltaba eran gente anónima: desde las víctimas del Bloody Sunday de 1972 (una marcha en Derry contra la política de internamientos sin juicio que terminó con el asesinato de 13 personas a cargo de paracaidistas británicos ${ }^{37}$ ) hasta los huelguistas de hambre del IRA e INLA en 1981, que demandaban estatus de prisioneros de guerra. Uno de ellos, Bobby Sands, es el principal icono del movimiento republicano. Su figura se contrapone a la de la Dama de Hierro, la primera ministra británica Margaret Thatcher, que no accedió a sus reivindicaciones y le habría dejado morir. A él y a otros nueve presos. Era un trasunto de los débiles contra los poderosos, David contra Goliat. Bobby Sands y los otros huelguistas fueron convertidos en mártires. Incluso a veces las representaciones del primero se parecían a Jesús y las de los segundos a sus apóstoles (fig. 2).

37 CONWAY, Brian: Commemoration and Bloody Sunday: Pathways of Memory, New York, Palgrave Macmillan, 2010. 


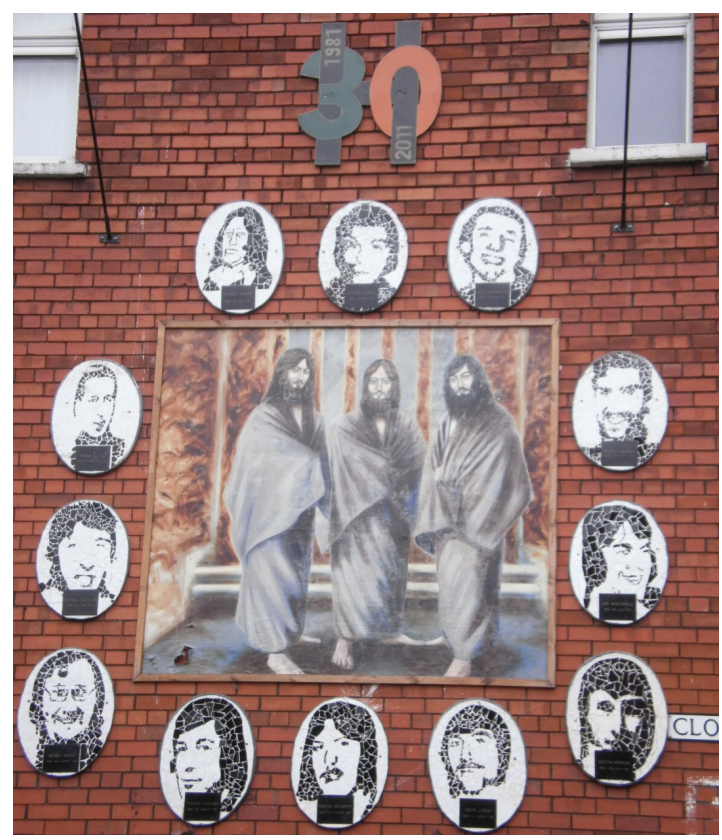

Fig. 2. Mural en recuerdo de los huelguistas de hambre del IRA e INLA muertos en 1981, Belfast (Foto: BvdL y RLR).

En el bando lealista también se valoraba mucho al individuo humilde que luchaba voluntariamente, incluso poniendo en riesgo su vida. Un buen ejemplo son los murales en honor a un chico de barrio, Stevie Topgun McKeag (presentado como comandante de Ulster Defence Association, una organización paramilitar), muerto en 2000 (fig. 3) o al "teniente" Jackie Coulter, asesinado el mismo año.

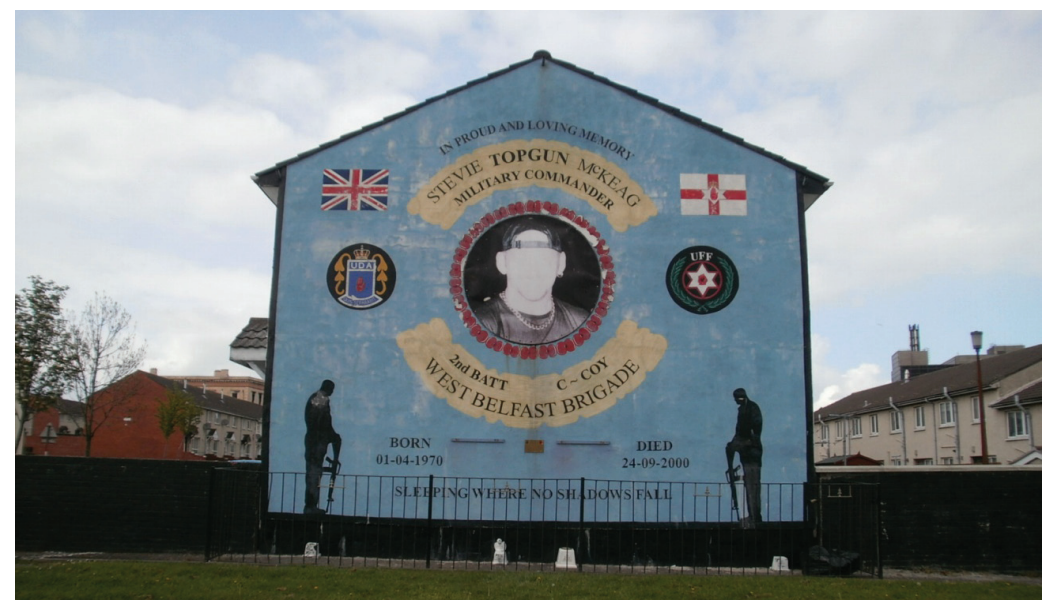

Fig. 3. Mural en conmemoración de Stevie Topgun McKeag, Belfast (Foto: BvdL y RLR). 
Ulster Volunteer Force insistía en que era una people's army, compuesta por el pueblo y para el pueblo. A través de la participación en organizaciones como IRA o UVF el "hombre normal" podía llegar a convertirse en uno de los protagonistas y, en caso de caer muerto, ser eternizado mediante el grabado de su nombre en las placas o monumentos de los varios Gardens of remembrance (fig. 4) salpicados por los pueblos y barrios del Ulster.

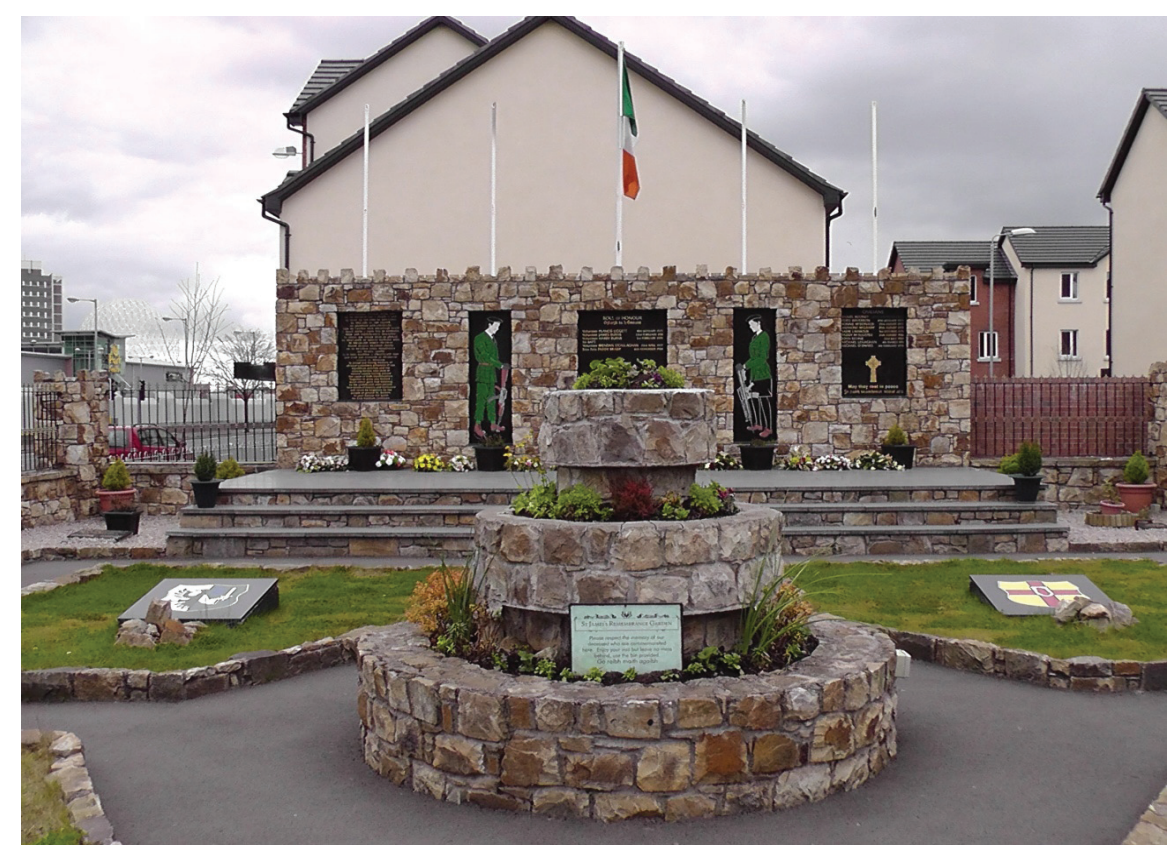

Fig. 4. Garden of Remembrance de los republicanos irlandeses en Belfast (Foto: BvdL y RLR).

Lo que más impacto emotivo pudo causar en ambos bandos fue el asesinato de niños en el conflicto. La muerte de los más pequeños, símbolos de la inocencia, era esgrimida para engrandecer la injusticia y las barbaridades cometidas por el "otro". Por ejemplo, un mural de 1982 en Derry representaba a Stephen McConomy, que perdió la vida por una bala de plástico. En él se juzgaba el acto con las siguientes palabras: "They call the killing of Stephen McConomy civil order" 38 . Otro mural lealista criticaba la violencia de los republicanos irlandeses mediante la imagen de un hombre llevando en brazos a un bebé muerto por una bomba.

Una de las principales lecciones que se transmiten en estos murales conmemorativos es la obligación de los vivos de no separarse del paradigma encarnado por los difuntos, quienes, si no, habrían fallecido en vano. Esto queda resumido en la frase inscrita en una placa ubicada en la fachada de la sede del Sinn Fein en Belfast: "We

38 ROLSTON, Bill: Drawing Support 2..., op. cit., p. 45. 
must take no steps backward,/ Our steps must be onward, for if we don't,/ the martyrs that died for you, for me,/ for this country, will haunt us forever" 39 .

Los disidentes republicanos del proceso de paz precisamente denuncian que la reciente evolución del Sinn Fein traiciona los sacrificios pasados. Ello sería visible en hechos como el reciente apretón de manos entre Martin McGuinness, viejo líder del IRA, y la reina Isabel II. Precisamente la actual autonomía norirlandesa ha tratado de paliar la sensación de incompatibilidad entre unas comunidades que, por cierto, siguen presentándose a sí mismas en esos términos.

Los lugares de memoria permanecen y transmiten una honda sensación comunitaria. Los ejemplos abundan. Así, varias placas en la zona católica de Falls Road recuerdan a "shopkeepers who, while serving our community, were murdered by British death Squads" o a los taxistas de la West Belfast Taxi Association asesinados a lo largo de los Troubles. Resalta aquí la importancia del giro local: muchas placas han sido colocadas justo donde las víctimas expiraron. La visualización de la comunidad en lo cotidiano se manifiesta, asimismo, en aceras o semáforos pintados con los colores de la bandera británica en los distritos unionistas, e incluye apelaciones a la participación popular en la práctica de deportes como el boxeo o el fútbol gaélico.

En suma, la existencia de dos comunidades político-religiosas, aparte de en su autopercepción, se aprecia en otros varios aspectos relacionados. Primero, en formas opuestas de comprender el pasado, presente y futuro del Ulster, lo que electoralmente se traduce en un escaso trasvase de voto de católicos a partidos unionistas y a la inversa. Segundo, en el aislamiento geográfico y cotidiano de la población: barrios segregados, educación no integrada, ausencia de matrimonios mixtos, amistades de la misma confesión y señalamiento de quienes se separan de esta norma ${ }^{40}$. Todo ello ha resultado en la creación de dos sociedades paralelas, con un exiguo roce entre ellas. Tercero, ese aislamiento se incrementó en las fases más crudas del conflicto por la actividad de organizaciones terroristas enfrentadas en una guerra civil velada, que estuvo acompañada por enfrentamientos callejeros en las interfaces entre barrios, levantamiento de muros (eufemísticamente denominados peace lines) para salvaguardar los límites entre unos distritos y otros...

Esas divisiones potenciadas durante décadas continúan vigentes ahora, en ausencia del terrorismo en su forma más cruda (persiste de un modo relativamente residual). Sobre todo reinan en los barrios de trabajadores más golpeados por la crisis económica y el desempleo crónico de la sociedad postindustrial, una parte de cuya población se mueve entre las drogas y la carencia de expectativas. De hecho una de las organizaciones republicanas que sigue atentando se centra en la "acción contra las drogas",

\footnotetext{
39 Texto dedicado a Máire Drumm, vicepresidenta del Sinn Fein, asesinada en Belfast por paramilitares lealistas el 28 de octubre de 1976.

40 Por poner unos ejemplos gráficos, el $90 \%$ de las viviendas sociales todavía están segregadas. El 93\% de los niños estudian separados en escuelas bien protestantes, bien católicas. Hay una corriente de enseñanza integrada, pero de momento solo incluye al 7\% de los estudiantes. Hoy en día hay más muros (48) que en 1998, cuando los Acuerdos de Viernes Santo (22). Y desde luego no se ha encontrado una solución para abordar el relato del pasado. Los datos en NOLAN, Paul: Northern Ireland Peace Monitoring Report: Number One 2012, Belfast, Community Relations Council, 2012.
} 
lo que no deja de ser una forma de control vecinal bajo el disfraz de ayudar a las comunidades locales a que sus jóvenes, el colectivo más expuesto, no se descarríen.

En algunos estudios universitarios se ha asumido la afirmación (relativamente divulgada a nivel social) de que en Euskadi existen dos comunidades ${ }^{41}$. Pero, al contrario que en Irlanda, solo hay una comunidad político-religiosa: la abertzale radical. El otro supuesto bloque "español" no es el fruto de una autopercepción, sino una etiqueta colgada desde fuera. Sí hubo una tradición vasco-española con una fuerte vocación movilizadora, visible en los años treinta del siglo $\mathrm{XX}^{42}$. Sin embargo, como hemos visto, dichas prácticas manifestantes desde abajo casi desaparecieron de la escena durante el franquismo.

La religiosidad de la citada comunidad abertzale se ha referido, más que al catolicismo (que también fue relevante, sobre todo en sus inicios), a una forma de comprender los asuntos públicos como una misión con un estandarte de la verdad absoluta (ETA) y un ente colectivo elevado a los altares: la patria ${ }^{43}$. El comunitarismo político-religioso ha sido palmario en el abertzalismo radical en el siguiente punto: la repetición semanal de ritos colectivos con una fuerte proyección pública, en los que los acólitos se han podido reconocer, fortaleciendo sus vínculos de pertenencia ${ }^{44}$. Manifestaciones y concentraciones por los presos de ETA, fiestas locales celebradas en un intenso ambiente de camaradería, conciertos, bares, homenajes a los últimos etarras excarcelados o muertos... Está por ver si dicho comunitarismo va relajándose tras el decreto del "cese definitivo" de la violencia de ETA en octubre de 2011.

Esa reiteración de convocatorias cotidianas organizadas desde abajo ha ido acompañada por otros aspectos que han robustecido una identidad excluyente. Primero, la tradicional renuncia tajante a establecer pactos con partidos "españoles". Segundo, la abundancia de locales de socialización y la estética frecuentemente compartida de sus asistentes, sobre todo entre los jóvenes. Tercero, la catalogación de los que han

41 Un ejemplo de esta tendencia se encuentra en KEATING, Michael: "Northern Ireland and the Basque Country", en John McGARRY (ed.): Northern Ireland and the Divided World: The Northern Ireland Conflict and the Good Friday Agreement in Comparative Perspective, Oxford, Oxford University Press, 2001, p. 191. Fuera del ámbito académico, Manu Escudero, entonces ligado al PCE-EPK, también interpretó que la sociedad vasca estaba dividida en dos: nacionalistas versus "otros vascos". Resulta discutible que todos los abertzales formen una comunidad, pero aún más lo es que el resto de los "otros vascos” estén integrados en otra. La obra de Escudero (Euskadi: Dos comunidades, San Sebastián, Haranburu, 1978), escrita en plena Transición democrática, encaja en un contexto de terrorismo etnicista en alza, un momento en el que se detectaba una fuerte tentación homogeneizadora del abertzalismo respecto al País Vasco.

42 UGARTE, Javier: La nueva Covadonga insurgente: Orígenes sociales y culturales de la sublevación en Navarra y el País Vasco, Madrid, Biblioteca Nueva, 1998.

43 CASQUETE, Jesús: En el nombre de Euskal Herria: La religión politica del nacionalismo vasco radical, Madrid, Tecnos, 2009. El reverso de la experiencia de ETAm-HB lo encontramos en la trayectoria de Euskadiko Ezkerra, que, procediendo del nacionalismo vasco más extremista, fue evolucionando en los años ochenta hacia el nacionalismo heterodoxo y la desacralización de la política. El caso ha sido tratado al detalle por FERNÁNDEZ SOLDEVILLA, Gaizka: Héroes, heterodoxos y traidores. Historia de Euskadiko Ezkerra (1974-1994), Madrid, Tecnos, 2013.

44 Es algo similar al caso norirlandés, donde, dependiendo de la zona, se constata lo siguiente: "Thus while the experiences of the Troubles had created a degree of mutual suspicion and hostility, it was the ongoing annual cycle of commemorations that ensured that tensions remained raw and unresolved", en JARMAN, Neil y BELL, John: "Routine Divisions: Segregation and Daily Life in Northern Ireland", Working Paper in British-Irish Studies, 87 (2009), p. 8. 
formado parte del colectivo y han decidido salir de él no como nuevos adversarios políticos, sino como disidentes y traidores al grupo de iguales, dentro de una cultura sectaria que hasta derivó en el asesinato de varios de ellos (el caso más conocido, aunque no el único, es el de Dolores González Katarain, Yoyes; el tema se estudia a fondo en otro artículo de este dossier). Cuarto, se ha dado una construcción no sólo de figuras referenciales para los propios sino, como ha estudiado Jesús Casquete, de héroes y mártires dispuestos a morir y matar por su nación; figuras que son elevadas al más alto rango en el escalafón patriótico. De ahí el lema "denok eman behar dugu zerbait gutxi batzuk dena eman behar ez dezaten"; es decir, todos tenemos que dar algo para que unos pocos no lo tengan que dar todo. Y quinto, ha habido una autopercepción de formar un bloque (el pueblo vasco más genuino) enfrentado a otro segmento tenido como homogéneo, los nacionalistas españoles (saco imaginario en el que se ha introducido a socialistas y populares), con el PNV situado de forma intermedia. Todo lo expuesto sirve para precisar que la única comunidad político-religiosa de Euskadi no ha integrado a los peneuvistas, sino que ha estado formada únicamente por los radicales ${ }^{45}$.

Cabe matizar que el abertzalismo radical no ha tomado la forma de una sociedad absolutamente paralela, sino parcialmente. Por ejemplo, a nivel educativo y laboral no se refleja una segregación. En Irlanda del Norte, "the work environment is generally neutral, but dominated by avoidance": se evita hablar de ciertos asuntos políticos. A diferencia de Euskadi, en el Ulster sí existen precauciones entre aquellos que trabajan en zonas donde predominan los miembros de la otra comunidad y a veces reina el miedo de ir al trabajo fuera de la propia área ${ }^{46}$.

En suma, en Euskadi la población se divide fundamentalmente por motivos políticos, con algunos ribetes en los que la fractura también se atisba a nivel social, aunque lejos de la realidad del Ulster. En todas las sociedades hay diferencias, pero solo en algunas surge un elemento identitario (étnico, religioso, social, racial... o varias de esas cuestiones al mismo tiempo) tan conflictivo que polariza radicalmente a los habitantes de un mismo territorio hasta incluso segregarlos en la vida cotidiana, creando un potente campo de fuerza en el ámbito político. Esto es algo que ocurre en Irlanda del Norte, Israel/Palestina o Sudáfrica. Es en estos últimos casos cuando puede hablarse de una sociedad profundamente dividida ${ }^{47}$.

Cabe plantearse por qué en muchas ocasiones los diversos elementos identitarios presentes en las sociedades modernas no las polarizan radicalmente. Sin profundizar en el análisis, se puede apuntar al papel del Estado (dependiendo de su reconocimiento de la pluralidad o de su conculcación de la misma, y de su percepción por las

45 Autores como Antonio Elorza ("Muerte anunciada", El Correo, 22 de agosto de 2012) consideran que en Euskadi la única comunidad política existente es la abertzale, que integraría tanto a moderados como a radicales. Estamos de acuerdo en que entre ambos sectores hay, como describió José Miguel de Azaola (El País Vasco, Madrid, Instituto de Estudios Económicos, 1988, p. 253), un aire de familia. Según nuestro criterio, ello da pie a hablar de una cultura política nacionalista con dos subculturas, encabezadas históricamente por el PNV y ETA, pero, reiteramos, no de una comunidad.

46 JARMAN, Neil y BELL, John: "Routine Divisions...", op. cit., p. 11.

47 GUELKE, Adrian: Politics in Deeply Divided Societies, Cambridge, Polity Press, 2012. Para un estudio comparativo de varios casos de sociedades profundamente divididas, vid. GUELKE, Adrian (ed.): Democracy and Ethnic Conflict: Advancing Peace in Deeply Divided Societies, London, Palgrave Macmillan, 2004. 
minorías como un ente legítimo o, al contrario, un "otro" agresivo) y a las representaciones culturales predominantes. En este último sentido, un potente y positivo mito de origen común ayuda a limar aristas potencialmente conflictivas; por ejemplo, en el caso de los Estados Unidos, la Guerra de Independencia y el "sueño americano", un relato al que podían agarrarse emigrantes de todas las procedencias.

Pese a sus similitudes, las comunidades político-religiosas de Euskadi y el Ulster no han sido iguales. La católico-republicana y la protestante-unionista han estado más replegadas sobre sí mismas que la abertzale radical respecto al resto de la sociedad vasca. El País Vasco está lejos de vivir diseccionado en función de la religión o la procedencia geográfica de sus habitantes. Hay cantidad de inmigrantes o descendientes de los mismos que votan a fuerzas nacionalistas vascas y, en menor medida, nativos con una buena colección de apellidos "oriundos" que eligen opciones no abertzales.

\section{4. ¿Cuándo y por qué surgieron las comunidades político-religiosas?}

La comunidad nacionalista vasca radical se fraguó en el tardofranquismo y eclosionó en la Transición. Las bases culturales del "nosotros", en las que cobró importancia una lectura revanchista de la Guerra Civil, fueron difundiéndose en los densos ámbitos de sociabilidad formal e informal del abertzalismo, y se vigorizaron ante sucesos como la muerte de Txabi Etxebarrieta (1968), el Proceso de Burgos (1970) y los fusilamientos de Txiki y Otaegi (1975). Aun así, el nacionalismo vasco radical solo se constituyó en una comunidad político-religiosa propiamente dicha tras la muerte de Franco, cuando se decidió proseguir con el terrorismo y cuando la vitalidad social del entramado radical se proyectó en el espacio público aprovechando las condiciones de la naciente democracia ${ }^{48}$.

La forja de dicha comunidad estuvo espoleada por factores estructurales, como el incremento de la inmigración al País Vasco, que ahondó el sentimiento de pérdida nacional de una generación abertzale, o la represión franquista, que favoreció las ansias de venganza colectiva. Pero los motivos de más peso que contribuyeron a este proceso fueron de tipo político: la adopción de la violencia como su principal seña de identidad y la necesidad de justificar esa elección tras la muerte de Franco, siendo los únicos que la defendían y creciendo así su autorreferencialidad.

ETA y su entorno civil no fueron el sustitutivo histórico de otra comunidad abertzale que habría actuado hasta la Guerra Civil: la ligada al PNV. La principal similitud entre ambas experiencias no es muy relevante: en ambos casos se formaron satélites que permitían a los jóvenes, mujeres, trabajadores, etc., socializarse en un ambiente políticamente determinado. Hay amplias diferencias que residen en lo que se hacía con esos satélites, qué visión de la realidad defendían y cómo se organizaban.

Hasta los años treinta el PNV se estructuró sectorialmente, pero permaneció abierto a pactos con fuerzas procedentes de distintas culturas políticas, con variaciones de-

48 FERNÁNDEZ SOLDEVILLA, Gaizka, y LÓPEZ ROMO, Raúl: Sangre, votos, manifestaciones: ETA y el nacionalismo vasco radical, 1958-2011, Madrid, Tecnos, 2012. 
pendiendo del momento. Además, como ha mostrado Mikel Aizpuru, los nacionalistas vascos participaban en asociaciones católicas junto con gente de otras ideologías, del mismo modo que "un mar de actos culturales, deportivos y festivos (...) permitieron que muchas personas se aproximasen al nacionalismo de forma indirecta" ${ }^{49}$. Por lo tanto no conviene trasladar la imagen de que el PNV era una agrupación sellada al contacto exterior. ETA y su entorno, por el contrario, fueron cerrándose sobre sí mismas, aparte de por su fanatismo ideológico, por la necesidad de evitar infiltraciones.

En el Ulster, a lo largo de esa "era de los extremos" que ha sido el siglo $\mathrm{XX}^{50}$, han existido dos comunidades político-religiosas que han descansado sobre las potentes líneas de fractura social a las que hemos hecho referencia (Iglesias enfrentadas, distintas procedencias geográficas). Ello es visible, por ejemplo, en las marchas conmemorativas de la batalla de Boyne que recorrían orgullosamente Irlanda y atravesaban desafiantes zonas predominantemente católicas. La celebración de la contienda se originó en el siglo XVIII y, finalmente, fue apropiada en el siglo XIX "to become a 'respectable' representation of Protestant identity, part of 'the Protestant tradition' in Ireland" 51 .

Dichas diferencias se exacerbaron con el desarrollo de un factor extra en los siglos XIX y XX: el nacionalismo, entrando en competencia las reclamaciones de independencia de toda Irlanda frente a las pretensiones de persistir con la unión a Gran Bretaña. La batalla de Boyne fue revisada como un episodio nacional dentro de la dualidad Irlanda versus Reino Unido, pese a que lo que entonces se dirimió fue un asunto dinástico y religioso.

A principios de la década de 1920, cuando se consagró la separación administrativa de la isla, los protestantes eran una mayoría significativa únicamente en el norte, en varios condados de la región del Ulster. En el nuevo Estado unionista se consolidó una comunidad político-religiosa dominante, que se sentía amenazada por una quinta columna interna: los católicos (una creciente minoría, dado su elevado índice de natalidad). Entre 1920 y 1972 Irlanda del Norte se rigió mediante gobiernos monocolor unionistas, en manos y al servicio de los protestantes. El movimiento por los derechos civiles de finales de los sesenta combatió la discriminación de los católicos, tanto en la arena política como en el mercado de trabajo ${ }^{52}$. No es ocioso recordar que el Nuevo Estado franquista (1936-1975) no fue un régimen contra los vascos (una parte significativa de los mismos apoyó el "Alzamiento Nacional"), sino contra el pluralismo; si bien la dictadura, al propagar por la fuerza una imagen unívoca de lo español, fue percibida por los abertzales como una condena contra Euskadi.

49 AIZPURU, Mikel: "Modelos de movilización y lugares de la memoria en el nacionalismo vasco. Los límites de una cultura política", Historia y Política, 15 (2006), pp. 130, 132 y cita en p. 137.

50 HOBSBAWM, Eric: Historia del siglo XX, 1914-1991, Barcelona, Crítica, 2012 [1994].

51 BRYAN, Dominic: Orange Parades..., op. cit., p. 29.

52 Las claves que explican el movimiento por los derechos civiles y el posterior salto a un conflicto violento han sido desarrolladas en castellano en ALONSO, Rogelio: Irlanda del Norte. Una historia de guerra y la búsqueda de la paz, Madrid, Editorial Complutense, 2001; SIERRA, Luis Antonio: Irlanda del Norte. Historia del conflicto, Madrid, Sílex, 1999; y LEONISIO, Rafael: "Del campo de batalla a las instituciones. Apuntes sobre la evolución ideológico-estratégica del movimiento republicano irlandés”, Inguruak, 47 (2009), pp. 67-85. 
En Irlanda del Norte las dos comunidades habían padecido fuertes enfrentamientos, que provocaron hasta 600 muertos entre los años 1920 y $1922^{53}$. La violencia volvió a intensificarse a finales de los sesenta, cuando estallaron los Troubles. El verano caliente de 1969 (fig. 5) se saldó con fuertes agresiones sectarias y migraciones de miles de personas de unos barrios a otros. Todo ello terminó derivando en un poderoso incremento de la homogeneización de la mayoría de los distritos de localidades como Belfast. La difusión de una espiral creciente de violencia bilateral fue fundamental como elemento potenciador de separaciones preexistentes. En 1969 reapareció el IRA (separado en un ala "oficial" y otra "provisional"). También nacieron nuevas organizaciones lealistas de carácter paramilitar, como UDA, en $1972^{54}$.

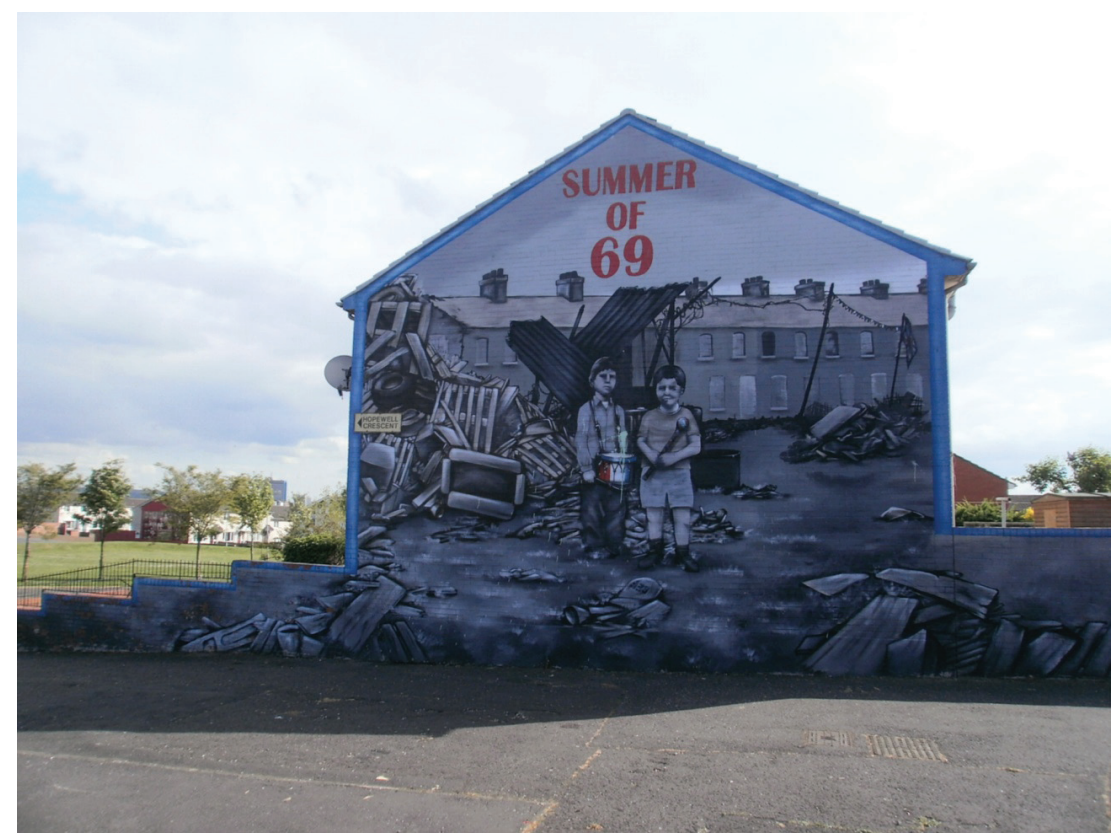

Fig. 5. Mural en conmemoración del verano de 1969 en una zona unionista de Belfast (Foto: BvdL y RLR).

La simultaneidad con la que arrancó la violencia de ETA(1968) y la última campaña del IRA (1969) es llamativa, pero no casual. Finales de los sesenta fue un momento en el que, tras la resaca post-68 de la última oleada de política radical en Europa occidental, proliferaron por doquier organizaciones terroristas que pretendían imponer mediante la fuerza sus ideas de redención de la clase trabajadora y de tal o cual nación. Ello fue así tanto en democracias como la República Federal de Alemania,

53 WALKER, Brian: A Political History of the Two Irelands..., op. cit., p. 7.

54 Ibidem, p. 117. 
Italia o Francia, como en dictaduras, caso de España, donde la respuesta brutal del franquismo no hizo más que enervar a la oposición ${ }^{55}$.

Los nacionalismos se basan en otros ejemplos tenidos como equiparables. A finales de la década de 1960 y durante los años setenta, para muchos los modelos a seguir eran guerrilleros y tercermundistas, de Vietnam a Cuba, de Palestina a Argelia. Se potenciaron los viajes y los contactos personales, el intercambio de información, la firma de manifiestos de "naciones oprimidas"... ${ }^{56}$. El momento histórico coincidió con la última etapa de la descolonización. Ésta dio pie al reimpulso de movimientos que buscaban aplicar la autodeterminación no solo a las colonias de África o Asia, sino también a determinados territorios de la propia Europa. Se trataba de rehacer el mapa del viejo continente poniendo las fronteras en base a las diferentes lenguas y etnias, en torno a una terminología común de "pueblos en lucha" y procesos de "liberación nacional".

\section{Euskadi y el Ulster: poco en común}

En el País Vasco y el Ulster la historia contemporánea ha alumbrado tres comunidades político-religiosas: la abertzale radical, la republicana irlandesa y la unionista británica. Las tres han compartido su fundamentalismo, incluyendo la asunción del terrorismo como forma de intervenir en los asuntos públicos. Pero, más allá de esto, ambos países no han tenido ni tienen mucho en común; ni cuando estaban inmersos en la violencia política, ni cuando la misma se ha desactivado. Entre 2007 y 2011 disidentes republicanos y lealistas provocaron doce víctimas mortales entre soldados, policías, civiles y miembros de las propias organizaciones paramilitares. En ese mismo periodo ETA mató a diez personas. Sin duda son muchas, muchísimas, porque una sola víctima ya es demasiado. Pero téngase en cuenta que hablamos de un país, España, que se enfrentaba a una organización que no estaba en alto el fuego frente a otro país, Irlanda del Norte, donde han transcurrido ya quince años de un proceso de paz formalmente exitoso. Estos datos no han de servir para minimizar el terrorismo de ETA, sino para comprobar la magnitud del reto de orden público que aún afronta el Ulster ${ }^{57}$.

Irlanda ha sido importante para el nacionalismo vasco prácticamente desde la fundación de esta corriente política. En la prensa abertzale, desde principios del siglo

55 Desarrolla este punto GONZÁLEZ CALLEJA, Eduardo: El laboratorio del miedo. Una historia general del terrorismo, de los sicarios a Al Qa'ida, Barcelona, Crítica, 2013.

56 Vid., por ejemplo, la Carta de Brest, 18 de abril de 1976, confirmación de la carta que data del 3 de febrero de 1974 ("Declaración sobre la lucha contra el colonialismo en Europa occidental"). Suscrita por partidos independentistas de Euskadi (HASI), Irlanda (Sinn Fein Workers Party - Official IRA), Cataluña (PSANP), Galicia (UPG), Bretaña, Gales y Cerdeña. El manifiesto dice así: "Conscientes del carácter universal del imperialismo y de la situación sumamente grave creada en esos países por la permanencia del sistema de opresión nacional y social resultante, declaran solemnemente la necesidad de una unión entre los pueblos oprimidos de Europa".

57 Los datos sobre el Ulster en NOLAN, Paul: Northern Ireland Peace Monitoring Report..., op. cit. Sobre las víctimas de ETA vid. DOMÍNGUEZ, Florencio, ALONSO, Rogelio y GARCÍA REY, Marcos: Vidas rotas. Historia de los hombres, mujeres y niños víctimas de ETA, Madrid, Espasa-Calpe, 2010. 
XX, pueden localizarse referencias a Irlanda y otros lugares del viejo continente, como Flandes, Hungría, Finlandia o Bretaña, mediante las que se buscaba reafirmar las propias demandas, presentándolas como algo no excepcional en el contexto internacional ${ }^{58}$. En realidad, Irlanda ha sido un ejemplo en toda Europa para activistas de "pequeñas naciones" que reclamaban independencia de grandes Estados. Ello se debe, primero, a la existencia de organizaciones tanto posibilistas como extremistas, en las que podían verse inspiradas sus homólogas extranjeras; y segundo, a la proximidad, al ser otro caso ubicado en Europa occidental, enfrentado a un Imperio por antonomasia: el británico. En último término, esa cercanía ha ayudado a la identificación entre las trayectorias del País Vasco y el Ulster mediante contactos personales ${ }^{59}$.

En 1998 los nacionalistas vascos, radicales y moderados, firmaron el Pacto de Estella, que surgió, no por casualidad, de las reuniones del llamado Foro de Irlanda. El momento de Estella significó el punto álgido de la utilización de Irlanda como ejemplo para Euskadi en el siglo XX. En el año 2000 el 33\% de los vascos encuestados para el Euskobarómetro aseguraba estar informado de la marcha del proceso de paz en el Ulster. Exactamente el mismo porcentaje defendía que entre Euskadi e Irlanda del Norte había muchas o bastantes similitudes. Otro $25 \%$ veía pocas semejanzas entre ambas realidades, el $16 \%$ no veía ninguna y un $24 \%$ confesaba no saber la respuesta ${ }^{60}$.

La preocupación por la posible "ulsterización" o "belfastización" del País Vasco, que ya había aparecido durante la Transición ${ }^{61}$, resurgió con fuerza a finales del siglo $\mathrm{XX}$, a cuenta del frentismo abertzale. La ruptura de la tregua de ETA en diciembre de 1999, y su consiguiente reinicio de una dura campaña de asesinatos, entre ellos de representantes electos no nacionalistas, acrecentaron el temor a que Euskadi se rompiera por abajo ${ }^{62}$.

Pero los abertzales, al establecer paralelismos, no reparaban tanto en la vertiente de división social de Irlanda del Norte cuanto en el modo como allí se estaría dando

58 Por poner varios ejemplos entre muchos posibles: "Nacionalismo bretón", Amayur, 17 de septiembre de 1932; "De Valera e Irlanda", Tierra Vasca, 6 (enero de 1933); "Finlandia antes de la consecución de la independencia", Euzkadi, 21 de julio de 1936.

59 NÚÑEZ SEIXAS, Xosé M.: "Irlanda", en PABLO, Santiago de, et al (coords.): Diccionario ilustrado de símbolos del nacionalismo vasco, Madrid, Tecnos, 2012, pp. 547-562. Vid. también las referencias que hace a Irlanda, a cuenta de las "historias de nacionalistas" (vascos e irlandeses), JUARISTI, Jon: El bucle melancólico. Historias de nacionalistas vascos, Madrid, Espasa Calpe, 1999.

60 Euskobarómetro, segunda oleada de 2000.

61 Se expresaron en ese sentido políticos de diversos signos, como Patxi Zabaleta (HB, Egin, 25 de marzo de 1979), Txiki Benegas (PSE-PSOE, El País, 21 de agosto de 1979) o el presidente del Gobierno de España, Adolfo Suárez (UCD), en OSORIO, Alfonso: Trayectoria política de un ministro de la Corona, Barcelona, Planeta, 1980, p. 264. En ese momento para todos ellos la situación del Ulster era una fuerte referencia negativa.

62 Temor que queda patente en la prensa de la época, en columnas como la de Carlos Martínez Gorriarán (“¿Dos comunidades enfrentadas?”, El Correo, 2 de marzo de 2000), escrita días después de que ETA matara al socialista Fernando Buesa y a su escolta, el ertzaina Jorge Díez, y de que se celebrara una manifestación de repulsa escindida en diferentes cortejos. Martínez Gorriarán, a la sazón profesor de filosofía en la Universidad del País Vasco, argumentaba que la ruptura de Euskadi en dos comunidades era algo buscado por ETA para imponer sus planteamientos políticos, ya que, de provocarse tal fisura, el bloque abertzale tendría una homogeneidad interna a la que el resto de la sociedad vasca, los no nacionalistas, no podrían aspirar, lo que beneficiaría los fines de los primeros. 
salida a la violencia. Lo que aquellos interpretaban era que el Gobierno británico había tenido que ceder en determinados aspectos para hacer posible la paz, concediendo una amnistía para los terroristas y autonomía para el Ulster a cambio del desarme. Los abertzales aseguraban que los gobiernos español y francés deberían tener esa flexibilidad política, con el horizonte de obtener la autodeterminación o la soberanía de Euskadi, una demanda que, según los mismos, había sido aceptada en Irlanda del Norte $^{63}$.

El problema de esta comparación es que en el País Vasco no se ha sufrido la violencia de dos comunidades enfrentadas desde abajo como en el Ulster, donde se liberó a los presos tanto de un bando como del otro, y desde 1979 está en vigor un amplio Estatuto de autonomía. Al contrario, el autogobierno norirlandés es joven: se aprobó en 1998, a raíz de los Acuerdos de Viernes Santo, y estuvo suspendido en cuatro ocasiones por el Gobierno británico, la última de ellas durante cinco años (2002-2007). Mientras tanto, Irlanda del Norte fue regida directamente desde Londres.

En el Ulster algunos de los lugares de memoria donde se exaltaba la violencia han sido ya sustituidos por otros que apelan a la reconciliación (aunque se sigue asumiendo que la sociedad norirlandesa está partida en dos) o que alaban determinados aspectos singulares culturales e históricos, pero sin carga agresiva. El lugar de memoria que mejor refleja los intentos de concordia es la estatua, ubicada en Derry, que representa a dos chicos que se dan la mano por encima de la brecha que los separa. La obra lleva el nombre Hands across the divide. En cuanto a las conmemoraciones, es visible "a new sense of shared identity between many people of very different national and political allegiances" en St. Patricks's Day y Remembrance Sunday, pero no ha ocurrido algo similar con la celebración de la batalla de Boyne ni con el Easter Rising ${ }^{64}$.

De hecho, marchas como las muchas que la Orden de Orange desarrolla siguen intoxicando las relaciones intercomunitarias, endureciendo las dicotomías y eternizando la segregación ${ }^{65}$. Además, pese a haberse alcanzado oficialmente la paz, prácticamente a diario se siguen reportando incidentes sectarios. Teniendo en cuenta todo esto, cabe concluir que los intentos de mimetizar en Euskadi la experiencia de los Acuerdos de Viernes Santo han estado más fundados en el voluntarismo político que en el conocimiento desprejuiciado de la compleja realidad norirlandesa.

\section{Bibliografía}

AIZPURU, Mikel: "Modelos de movilización y lugares de la memoria en el nacionalismo vasco. Los límites de una cultura política”, Historia y Política, 15 (2006), pp. 117-146.

63 Rogelio Alonso recuerda que el tipo de autodeterminación que se pactó en Stormont había sido históricamente despreciado por los republicanos porque, al incorporar el veto unionista, socavaba su tradicional reivindicación innegociable de una Irlanda unida. Vid. ALONSO, Rogelio: "Divergencias entre Irlanda del Norte y el País Vasco en la búsqueda de la paz", Papeles de Ermua, 3 (2002), pp. 156-161.

64 WALKER, Brian: A Political History of the Two Irelands..., op. cit., p. 176.

65 JARMAN, Neil y BELL, John: "Routine Divisions...", op. cit., p. 8. 
ALONSO, Rogelio: Irlanda del Norte. Una historia de guerra y la búsqueda de la paz, Madrid, Editorial Complutense, 2001.

ALONSO, Rogelio: "Divergencias entre Irlanda del Norte y el País Vasco en la búsqueda de la paz", Papeles de Ermua, 3 (2002), pp. 156-161.

ANGELIS, Vangelis: "Seis entierros y un réquiem: El ceremonial de la muerte política en la Grecia de 1936", en Jesús CASQUETE y Rafael CRUZ (eds.): Políticas de la muerte: Usos y abusos del ritual fúnebre en la Europa del siglo XX, Madrid, Los Libros de la Catarata, 2009, pp. 215-245.

AZAOLA, José Miguel de: El País Vasco, Madrid, Instituto de Estudios Económicos, 1988.

BARLEY, Nigel: Bailando sobre la tumba: Encuentros con la muerte, Barcelona, Editorial Anagrama, 2000.

BERTMAN, Sandra L.: "Comunicación con los muertos: experiencia en el arte, la literatura y el canto", en Robert KASTENBAUM (dir.): Entre la vida y la muerte, Barcelona, Herder, 1984, pp. 169-203.

BLACK, Monica: Death in Berlin: From Weimar to Divided Germany, Cambridge, Cambridge University Press, 2010.

BRYAN, Dominic: Orange Parades: The Politics of Ritual, Tradition and Control, London, Pluto Press, 2000.

CASQUETE, Jesús: "El poso agridulce de la ausencia: Vectores de las políticas de la muerte", en Jesús CASQUETE y Rafael CRUZ (eds.): Políticas de la muerte: Usos y abusos del ritual fúnebre en la Europa del siglo XX, Madrid, Los Libros de la Catarata, 2009, pp. 335-349.

- En el nombre de Euskal Herria: La religión politica del nacionalismo vasco radical, Madrid, Tecnos, 2009.

CONWAY, Brian: Commemoration and Bloody Sunday: Pathways of Memory, New York, Palgrave Macmillan, 2010.

DOMÍNGUEZ, Florencio, ALONSO, Rogelio y GARCÍA REY, Marcos: Vidas rotas. Historia de los hombres, mujeres y niños víctimas de ETA, Madrid, Espasa-Calpe, 2010.

ESCUDERO, Manu: Euskadi: Dos comunidades, San Sebastián, Haranburu, 1978.

FERNÁNDEZ DEL RIESGO, Manuel: Antropología de la muerte: Los límites de la razón y el exceso de la religión, Madrid, Síntesis, 2007.

FERNÁNDEZ SOLDEVILLA, Gaizka: Héroes, heterodoxos y traidores. Historia de Euskadiko Ezkerra (1974-1994), Madrid, Tecnos, 2013.

FERNÁNDEZ SOLDEVILLA, Gaizka, y LÓPEZ ROMO, Raúl: Sangre, votos, manifestaciones: ETA y el nacionalismo vasco radical, 1958-2011, Madrid, Tecnos, 2012.

FORTY, Adrian y KÜCHLER, Susanne (eds.): The Art of Forgetting, Oxford, Berg, 1999.

GONZÁLEZ CALLEJA, Eduardo: El laboratorio del miedo. Una historia general del terrorismo, de los sicarios a Al Qa'ida, Barcelona, Crítica, 2013.

GUELKE, Adrian: Politics in Deeply Divided Societies, Cambridge, Polity Press, 2012.

- (ed.): Democracy and Ethnic Conflict: Advancing Peace in Deeply Divided Societies, London, Palgrave Macmillan, 2004.

GURRUCHAGA, Iñigo: El modelo irlandés. Historia secreta de un proceso de paz, Barcelona, Península, 1998.

HOBSBAWM, Eric: Historia del siglo XX, 1914-1991, Barcelona, Crítica, 2012 [1994]. 
HORDAGO (comp.): Documentos Y, San Sebastián, Lur, 1979.

IGLESIAS, M. ${ }^{a}$ Antonia: Memoria de Euskadi. La terapia de la verdad: todos lo cuentan todo, Madrid, Aguilar, 2009.

JARMAN, Neil y BELL, John: "Routine Divisions: Segregation and Daily Life in Northern Ireland", Working Paper in British-Irish Studies, 87 (2009).

JUARISTI, Jon: El bucle melancólico. Historias de nacionalistas vascos, Madrid, Espasa Calpe, 1999.

KEATING, Michael: "Northern Ireland and the Basque Country", en John McGARRY (ed.): Northern Ireland and the Divided World: The Northern Ireland Conflict and the Good Friday Agreement in Comparative Perspective, Oxford, Oxford University Press, 2001, pp. 181-206.

LEONISIO, Rafael: "Del campo de batalla a las instituciones. Apuntes sobre la evolución ideológico-estratégica del movimiento republicano irlandés”, Inguruak, 47 (2009), pp. 67 85 .

MOLINA, Fernando: "De la historia a la memoria. El carlismo y el problema vasco (18681979)", en VVAA: El carlismo en su tiempo: geografías de la contrarrevolución, Pamplona, Gobierno de Navarra, 2008, pp. 167-204.

- “El nacionalismo español y la 'guerra del Norte', 1975-1981”, Historia del Presente, 13 (2009), pp. 41-54.

- “¿De dónde salieron las banderas? Reflexiones sobre 'la Roja', los vascos y el patriotismo español”, Cuadernos de Alzate, 44 (2011), pp. 31-46.

- "La nación desde abajo. Nacionalización, individuo e identidad nacional", Ayer, 90 (2013), pp. 39-63.

MULKAY, Michael: "Social Death in Britain", en David CLARK (ed.): The Sociology of Death: Theory, Culture, Practice, Oxford, Blackwell, 1993.

NOLAN, Paul: Northern Ireland Peace Monitoring Report: Number One 2012, Belfast, Community Relations Council, 2012.

NÚÑEZ SEIXAS, Xosé M.: "Irlanda", en PABLO, Santiago de, et al (coords.): Diccionario ilustrado de símbolos del nacionalismo vasco, Madrid, Tecnos, 2012, pp. 547-562.

OSORIO, Alfonso: Trayectoria política de un ministro de la Corona, Barcelona, Planeta, 1980.

PÉREZ, José Antonio: Los años del acero: La transformación del mundo laboral en el área industrial del Gran Bilbao (1958-1977). Trabajadores, convenios y conflictos, Madrid, Biblioteca Nueva, 2001.

- "De la comunidad nacional a la comunidad de propietarios. Los límites del nacional sindicalismo", en Luis CASTELLS, Arturo CAJAL y Fernando MOLINA (eds.): El País Vasco y España: Identidades, nacionalismos y Estado (siglos XIX y XX), Bilbao, Universidad del País Vasco, 2007, pp. 215-247.

RADER, Olaf B.: "Viejos huesos con nuevos significados", en Jesús CASQUETE y Rafael CRUZ (eds.): Políticas de la muerte: Usos y abusos del ritual fúnebre en la Europa del siglo XX, Madrid, Los Libros de la Catarata, 2009, pp. 23-37.

ROLSTON, Bill: Drawing Support 2: Murals of War and Peace, Belfast, Beyond the Pale Publications, 1995.

- "Changing the Political Landscape: Murals and Transition in Northern Ireland", Irish Studies Review, 11-1 (2003), pp. 3-16. 
SAZ, Ismael: "Las culturas de los nacionalismos franquistas", Ayer, 71 (2008), pp. 153-174.

SIERRA, Luis Antonio: Irlanda del Norte. Historia del conflicto, Madrid, Sílex, 1999.

SMITH, Lacey Baldwin: Fools, Martyrs, Traitors: The Story of Martyrdom in the Western World, Evanston, Illinois, Northwestern University Press, 1997.

STYNEN, Andreas: Een Geheugen in Fragmenten: Heilige Plaatsen van de Vlaamse Beweging, Tielt, Lannoo, 2005.

THOMAS, Louis-Vincent: Rites de mort: Pour la paix des vivants, Paris, Fayard, 1985.

UGARTE, Javier: La nueva Covadonga insurgente: Orígenes sociales y culturales de la sublevación en Navarra y el País Vasco, Madrid, Biblioteca Nueva, 1998.

VERDERY, Katherine: The Political Lives of Dead Bodies: Reburial and Postsocialist Change, New York, Columbia University Press, 1999.

WALKER, Brian: A Political History of the Two Irelands: From Partition to Peace, Basingstoke/ New York, Palgrave Macmillan, 2012. 